\title{
Emerging of unexpected extra efficiency
}

Researcher and inventor: Umer Farooq

\section{Abstract}

Substantial amount of extra efficiency emerged during experiments on repulsion and attraction forces between an electromagnet and a permanent magnet. Repeatedly repeatable experiments verified emerging of this extra efficiency undeniably. Whenever both current (of electromagnet) and flux (of permanent magnet) were enhanced, efficiency jumped higher. Output must increase because of enhanced current and flux but from where does the extra efficiency come? $I^{\wedge} 2 \mathrm{R}$ loss increases as a result of increment in current so efficiency must drop but it increases instead! No rule of electromagnetism justifies this extra efficiency. A theory has also been evolved to interpret the results of experiments. In this theory laws of motion have been applied on magnetic force. The laws of motion justify the extra efficiency sufficiently. According to the laws of motion, the emerging of the extra efficiency is absolutely natural.

\section{Introduction}

This paper presents the essence of a research that took 14 years. The research was conducted to explore maximum strength of attraction and repulsion forces between an electromagnet and a permanent magnet.

I have developed a device. Using this device one electromagnet and one permanent magnet can repel or attract each other in a controlled situation. This device gathers necessary data of a repulsion or attraction interaction. Input and output is calculated after an interaction is completed. Figure:

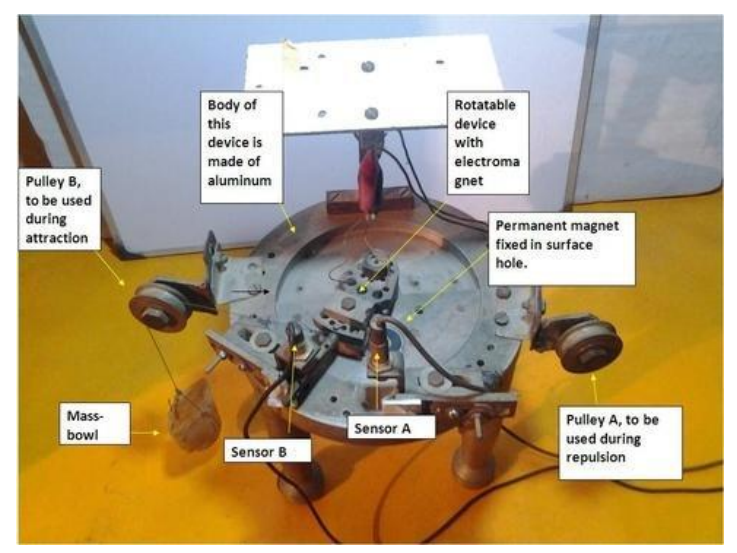

\section{A series of 3 experiments was conducted using the magnetic power measuring device.}

In the three experiments: at different levels of input current, an electromagnet was interacted with permanent magnets of different strength.

Experiment 1: using a specific amount of input current, an electromagnet interacted with a single permanent magnet. Data was collected. 
Experiment 2: using a higher amount of current, the same electromagnet interacted with a permanent magnet of double strength. The same interactions were repeated. Data was collected using the same method.

Experiment 3: using even higher than both of the previous amounts of current, the same electromagnet interacted with a permanent magnet of triple strength. The same interactions were repeated. Data was collected using the same method.

Comparison of the data of the interactions showed that at enhanced current levels, while stronger permanent magnet was used, efficiency exceeded extraordinarily.

In experiment 2, two permanent magnets were used instead of one. Double permanent magnet attracted the electromagnet with double force. Double input must have been needed for repulsion in this case. Efficiency of experiment 2 must remain nearly the same as that of experiment, 1; but the result was absolutely different.

The experiment 2 used a very small amount of more input power than that was used by experiment 1 but provided double amount of output of attraction.

Resultantly, cycle of repulsion and attraction of this experiment provided heavy amount of more efficiency than that of experiment 1.

Experiment 3 was a verifying experiment. This experiment verified that whenever current and pm flux is enhanced, the efficiency always increases accordingly, continuously and substantially.

Greater output power was a natural result of greater current and stronger permanent magnet, but what was the reason of extraordinary increment in efficiency?

$I^{\wedge} 2 R$ loss must increase as a result of increment in current so efficiency must drop but it increases instead! No present rule of electromagnetism justifies this extra efficiency.

Surprisingly, interpretation of the results of the experiments in accordance with the laws of motion justifies the extraordinary efficiency sufficiently. According to the laws of motion, the extraordinary efficiency must appear naturally.

\section{Description}

\section{Magnetic power measuring device}

I have developed a device. Using this device one electromagnet and one permanent magnet can repel or attract each other in a controlled situation. This device gathers necessary data of a repulsion or attraction interaction. Input and output is calculated after an interaction is completed.

A series of 3 experiments was conducted using the magnetic power measuring device. 


\section{The three experiments}

- Three experiments were conducted on attraction and repulsion between an electromagnet and a permanent magnet.

- Electromagnet and permanent magnet were interacted on the magnetic power measuring device.

- During the experiments, the same electromagnet was supplied different amounts of current.

- Different amounts of flux of permanent magnets were used in each experiment. For this purpose more pieces of permanent magnet were added to the primary permanent magnet.

- In each of the three experiments, the electromagnet and the permanent performed three inter actions:

- Both of them repelled each other. Data was collected.

○ Both of them attracted each other without current. Data was collected.

- Both of them attracted each other with current. Data was collected.

- The same input was used for repulsion and attraction of an experiment.

- Air gap between electromagnet and permanent magnet during all the three experiment remained fixed. This was $1 \mathrm{~mm}$.

\section{Magnetic configuration of experiment number 1:}

- All data of this experiment has been given in table number, 4 .

- The same electromagnet was used that has been specified in the part of experimental devices.

- A specific amount of input current was applied to the electromagnet.

- One permanent magnet was used. This permanent magnet has been specified in the part of experimental devices. Figure:

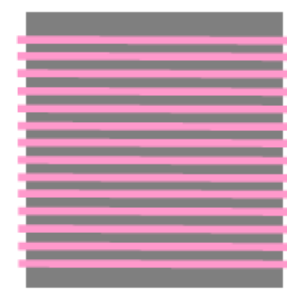




\section{Magnetic configuration of experiment number 2:}

- All data of this experiment has been given in table number, 5 .

- The same electromagnet was used. A higher amount of current was applied to the electromagnet.

- Two permanent magnets of the same specification were used. Figure:

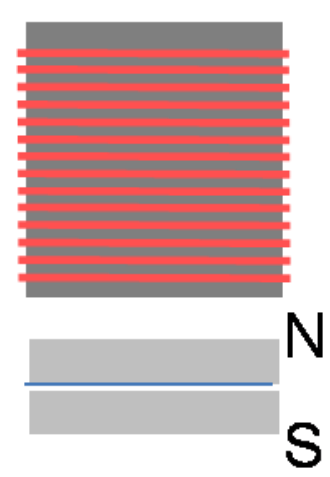

\section{Magnetic configuration of experiment number 3:}

- All data of this experiment has been given in table number, 6 .

- The same electromagnet was used. Higher than both of the previous amounts of current was applied to the electromagnet.

- Three permanent magnets of the same specification were used. Figure:
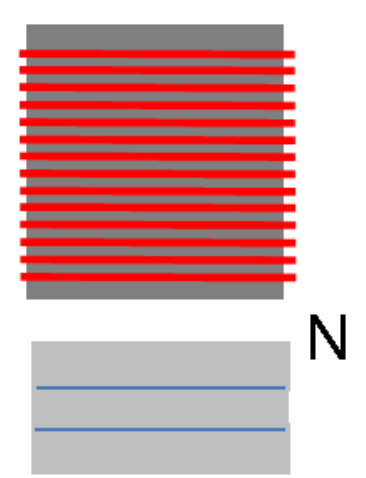

$S$

\section{Comparison of results of the experiments}

1. Comparison of efficiencies of all the three experiments when attraction happened without current

(Data for this comparison has been given in table 1) 
- During each of these three experiments an interaction of attraction without current was also conducted. Current was given for repulsion only. Repulsion happened and electromagnet crossed away permanent magnet. When current was put-off, permanent magnet attracted the iron of electromagnet back automatically. This way a complete cycle of repulsion and attraction happened.

- Real output of each of these interactions is a combination of output powers of both repulsion with current and attraction without current.

- Comparison of data of such interactions clearly shows gradual increment in the efficiencies.

\section{Very important finding}

On one hand we get full reward in the form of full repulsion force in return of any amount of input current. On the other hand we get huge amount of PM attraction for free. Explanation:

In experiment 1, lower quantity of input current was applied and lower quantity of repulsion force was got.

In experiment 2, higher quantity of input current was applied and higher quantity of repulsion force was got.

In experiment 3, highest of all the three quantities of input current was applied and highest of all the three amounts of repulsion force was got.

In all the experiments, we get volume of repulsion force in accordance with the volume of input current. Both of the quantities are directly proportional. If input current is lower, we get lower output power of repulsion force. If input current is higher we get higher output power of repulsion force. In other words, efficiencies of input current remains approximately similar to each other in all the three experiment.

We have got higher amount of repulsion force against higher payment (higher amount of input current). Now we cannot get any additional force according to present interpretations of law of conservation of energy.

In experiment 2, two permanent magnets were used instead of one. Double input must have been needed for repulsion in this case. Efficiency of experiment 2 must have remained nearly the same as that of experiment, 1 ; but the result was absolutely different.

The experiment 2 used a small amount of more input power than that was used by experiment 1 , but pushed double amount of PM flux. Pushing double amount of PM flux resulted in achieving double attraction. This experiment provided a heavy amount of output of attraction without current. Resultantly, heavy amount of additional efficiency of a complete cycle was got in this experiment.

\section{Where the energy does come from to create the additional efficiency?}


Greater output power was a natural result of greater current but what was the cause of greater efficiency?

Objection: How can one say that additional efficiency is appearing gradually; it may be inefficiency of input power in experiment 1 ?

Answer: Input power has been given for repulsion only. In experiment 1, efficiency of input current for repulsion is higher than that of experiment 2 and 3, so any factor of inefficiency is out of question.

Table 1

Electromagnet: the same

\begin{tabular}{|c|c|c|c|c|c|c|c|}
\hline 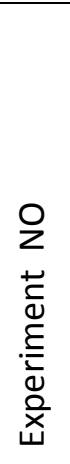 & $\begin{array}{l}\text { Number of } \\
\text { Permanent } \\
\text { magnets }\end{array}$ & $\begin{array}{l}\text { Input } \\
\text { Watt- } \\
\text { second } \\
\text { for } \\
\text { repulsion }\end{array}$ & $\begin{array}{l}\text { Output } \\
\text { repulsion } \\
\text { power }\end{array}$ & $\begin{array}{l}\text { Efficiency } \\
\text { of current } \\
\text { for } \\
\text { repulsion }\end{array}$ & $\begin{array}{l}\text { Output } \\
\text { attraction } \\
\text { power of } \\
\text { permanent } \\
\text { magnet } \\
\text { only } \\
\text { (without } \\
\text { current) }\end{array}$ & Total output & $\begin{array}{l}\text { Efficiency } \\
\text { of a } \\
\text { complete } \\
\text { cycle of } \\
\text { repulsion } \\
\text { and } \\
\text { attraction }\end{array}$ \\
\hline 1 & $\begin{array}{l}\text { Only one } \\
\text { saturated } \\
\text { permanent } \\
\text { magnet }\end{array}$ & 0.417 & 0.075 & 0.17977 & 0.075 & $\begin{array}{l}0.075+0.075 \\
=0.150\end{array}$ & 0.359 \\
\hline 2 & $\begin{array}{l}\text { Two } \\
\text { saturated } \\
\text { permanent } \\
\text { magnets } \\
\text { were } \\
\text { added } \\
\text { together }\end{array}$ & 0.584 & 0.085 & 0.14667 & 0.176 & $\begin{array}{l}0.176+0.085 \\
=0.262\end{array}$ & 0.448 \\
\hline 3 & $\begin{array}{l}\text { Three } \\
\text { saturated } \\
\text { permanent } \\
\text { magnets } \\
\text { were } \\
\text { added } \\
\text { together }\end{array}$ & 0.646 & 0.100 & 0.15476 & 0.314 & $\begin{array}{l}0.314+0.100 \\
=0.414\end{array}$ & 0.641 \\
\hline
\end{tabular}




\section{Comparison of efficiencies of all the three experiments when attraction happened with current}

(Data for this comparison has been given in table 2)

- During all the three experiments, interactions of attraction with current were also conducted.

- In all these interactions, output attraction power is a combination of attraction of permanent magnet and attraction of electromagnet.

- Combined efficiencies of repulsion and attraction of these cycles remained lower than those of the cycles that comprised upon attraction-without- current.

Reason: attraction of PM happened totally freely when permanent magnet attracted only iron (electromagnet without current). This free attraction created the extra efficiency of a full cycle of repulsion and attraction-without- current.

\section{- Gradual increment in efficiencies remains intact.}

Table 2

\section{Electromagnet: the same}

Permanent magnets: same as given in table 1

\begin{tabular}{|c|c|c|c|c|c|c|c|c|c|}
\hline 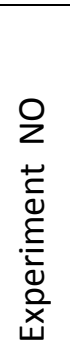 & $\begin{array}{l}\text { Input } \\
\text { Watt- } \\
\text { secon } \\
d \text { for } \\
\text { repul } \\
\text { sion }\end{array}$ & $\begin{array}{l}\text { Outp } \\
\text { ut } \\
\text { repul } \\
\text { sion } \\
\text { powe } \\
\text { r }\end{array}$ & $\begin{array}{l}\text { Efficie } \\
\text { ncy of } \\
\text { curre } \\
\text { nt for } \\
\text { repuls } \\
\text { ion }\end{array}$ & $\begin{array}{l}\text { Input } \\
\text { Watt- } \\
\text { secon } \\
d \text { for } \\
\text { attrac } \\
\text { tion }\end{array}$ & $\begin{array}{l}\text { Outpu } \\
\mathrm{t} \\
\text { attrac } \\
\text { tion } \\
\text { power }\end{array}$ & $\begin{array}{l}\text { Efficie } \\
\text { ncy of } \\
\text { attrac } \\
\text { tion }\end{array}$ & $\begin{array}{l}\text { Total } \\
\text { input }\end{array}$ & Total output & $\begin{array}{l}\text { Efficiency of a } \\
\text { complete cycle } \\
\text { of repulsion and } \\
\text { attraction }\end{array}$ \\
\hline 1 & $\begin{array}{l}0.417 \\
36\end{array}$ & $\begin{array}{l}0.075 \\
03\end{array}$ & $\begin{array}{l}0.179 \\
77\end{array}$ & $\begin{array}{l}0.417 \\
36\end{array}$ & $\begin{array}{l}0.162 \\
31\end{array}$ & $\begin{array}{l}0.388 \\
89\end{array}$ & $\begin{array}{l}0.4173 \\
* 2=0.8 \\
346\end{array}$ & $\begin{array}{l}0.07503+0.16231 \\
=0.23734\end{array}$ & $\begin{array}{l}0.23734 / 0.8346 \\
=0.28437\end{array}$ \\
\hline 2 & $\begin{array}{l}0.584 \\
64\end{array}$ & $\begin{array}{l}0.085 \\
75\end{array}$ & $\begin{array}{l}0.146 \\
67\end{array}$ & $\begin{array}{l}0.584 \\
64\end{array}$ & $\begin{array}{l}0.348 \\
25\end{array}$ & $\begin{array}{l}0.595 \\
66\end{array}$ & $\begin{array}{l}0.5846 \\
* 2=1.1 \\
692\end{array}$ & $\begin{array}{l}0.08575+0.34825 \\
=0.434\end{array}$ & $\begin{array}{l}0.434 / 1.1692= \\
0.37119\end{array}$ \\
\hline 3 & $\begin{array}{l}0.646 \\
38\end{array}$ & $\begin{array}{l}0.100 \\
04\end{array}$ & $\begin{array}{l}0.154 \\
76\end{array}$ & $\begin{array}{l}0.646 \\
38\end{array}$ & $\begin{array}{l}0.610 \\
45\end{array}$ & $\begin{array}{l}0.944 \\
41\end{array}$ & $\begin{array}{l}0.6463 \\
* 2=1.2 \\
926\end{array}$ & $\begin{array}{l}0.10004+0.61045 \\
=0.71049\end{array}$ & $\begin{array}{l}0.71049 / 1.2926 \\
=0.54965\end{array}$ \\
\hline
\end{tabular}




\section{3: Comparison of efficiencies of current-only}

(Data for this comparison has been given in table 3)

- In this method of comparison, output attraction power of permanent magnet has been subtracted and attraction power of only electromagnet is calculated.

- Gradual increment in efficiencies remains intact. Because higher level of current activated higher amount of unused PM flux. [When permanent magnet attracts only iron (electromagnet without current) large part of the PM flux remains unused.]

Table 3

\begin{tabular}{|c|c|c|c|c|c|c|c|c|c|}
\hline \multicolumn{10}{|c|}{$\begin{array}{l}\text { Electromagnet: the same } \\
\text { Permanent magnets: same as given in table } 1\end{array}$} \\
\hline 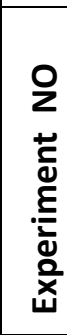 & $\begin{array}{l}\text { Input } \\
\text { Watt- } \\
\text { secon } \\
\text { d for } \\
\text { repul } \\
\text { sion }\end{array}$ & $\begin{array}{l}\text { Outp } \\
\text { ut } \\
\text { repul } \\
\text { sion } \\
\text { powe } \\
r\end{array}$ & $\begin{array}{l}\text { Efficie } \\
\text { ncy of } \\
\text { curre } \\
\text { nt for } \\
\text { repuls } \\
\text { ion }\end{array}$ & $\begin{array}{l}\text { Input } \\
\text { Watt- } \\
\text { secon } \\
\text { d for } \\
\text { attrac } \\
\text { tion }\end{array}$ & $\begin{array}{l}\text { Output } \\
\text { attracti } \\
\text { on } \\
\text { power } \\
\text { of } \\
\text { current } \\
\text { only }\end{array}$ & $\begin{array}{l}\text { Efficie } \\
\text { ncy of } \\
\text { curre } \\
\text { nt for } \\
\text { attrac } \\
\text { tion }\end{array}$ & $\begin{array}{l}\text { Total } \\
\text { input }\end{array}$ & Total output & $\begin{array}{l}\text { Efficiency of } \\
\text { current applied } \\
\text { to a complete } \\
\text { cycle of } \\
\text { repulsion and } \\
\text { attraction }\end{array}$ \\
\hline 1 & $\begin{array}{l}0.417 \\
36\end{array}$ & $\begin{array}{l}0.075 \\
03\end{array}$ & $\begin{array}{l}0.179 \\
77\end{array}$ & $\begin{array}{l}0.417 \\
36\end{array}$ & $\begin{array}{l}0.0872 \\
8125\end{array}$ & $\begin{array}{l}0.209 \\
12\end{array}$ & $\begin{array}{l}0.4173 \\
* 2=0.8 \\
346\end{array}$ & $\begin{array}{l}0.07503+0.08728 \\
=0.16231\end{array}$ & $\begin{array}{l}0.16231 / 0.8346 \\
=0.19447\end{array}$ \\
\hline 2 & $\begin{array}{l}0.584 \\
64\end{array}$ & $\begin{array}{l}0.085 \\
75\end{array}$ & $\begin{array}{l}0.146 \\
67\end{array}$ & $\begin{array}{l}0.584 \\
64\end{array}$ & 0.1715 & $\begin{array}{l}0.293 \\
34\end{array}$ & $\begin{array}{l}0.5846 \\
* 2=1.1 \\
692\end{array}$ & $\begin{array}{l}0.08575+0.1715 \\
=0.25725\end{array}$ & $\begin{array}{l}0.25725 / 1.1692 \\
=0.22002\end{array}$ \\
\hline 3 & $\begin{array}{l}0.646 \\
38\end{array}$ & $\begin{array}{l}0.100 \\
04\end{array}$ & $\begin{array}{l}0.154 \\
76\end{array}$ & $\begin{array}{l}0.646 \\
38\end{array}$ & $\begin{array}{l}0.2960 \\
4\end{array}$ & $\begin{array}{l}0.457 \\
99\end{array}$ & $\begin{array}{l}0.6463 \\
* 2=1.2 \\
926\end{array}$ & $\begin{array}{l}0.10004+0.29604 \\
=0.39608\end{array}$ & $\begin{array}{l}0.39608 / 1.2926 \\
=0.30642\end{array}$ \\
\hline
\end{tabular}

\section{Result}

When interacting electromagnet was provided more current and stronger permanent magnet was used, efficiency of interaction increased strongly.

Special note:

Greater output power was a natural result of greater current and stronger permanent magnet, but emerging of extraordinary efficiency was absolutely unexpected. 


\section{Justification of the unexpected efficiency}

A very common phenomenon in electromagnetism is responsible for the weak efficiencies. If this phenomenon is reduced, the extra efficiency appears naturally. However this phenomenon is too simple to be detected. That is why its importance has never been judged. Before further proceedings, I think it is very important to explain the phenomenon from its roots.

For, without understanding the matter from the roots, even most experienced scientist and engineers may experience difficulty to understand the real output of all this work.

\section{Prior art: the phenomenon 'attraction during repulsion'}

1. When no current is supplied to an electromagnet, it is merely a piece of iron. A permanent magnet will attract this piece of iron forcefully. Figure:

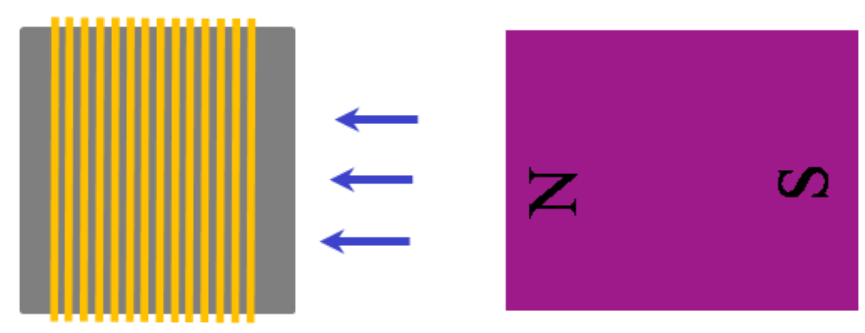

2. If only $1 / 3$ part of the iron core is magnetized, its $2 / 3$ part will remain un-magnetized.

- Naturally the permanent magnet will attract the $2 / 3$ iron strongly. Repulsion will be very weak.

Figure: 


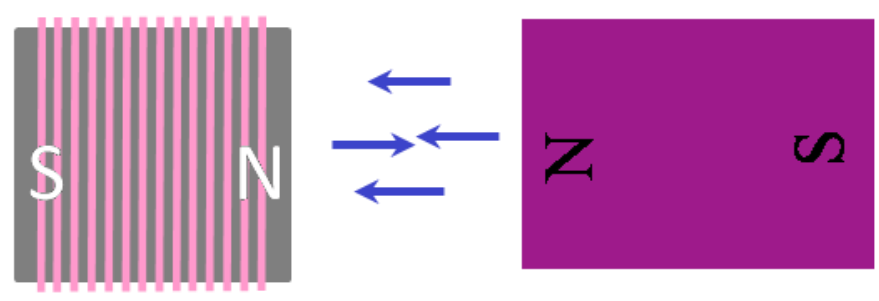

3. If $2 / 3$ part of the iron core is magnetized, its $1 / 3$ part will remain un-magnetized.

- The permanent magnet will continue attracting rest $1 / 3$ part of iron. However the permanent magnet will find a smaller part to attract. Repulsion will become stronger. Figure:

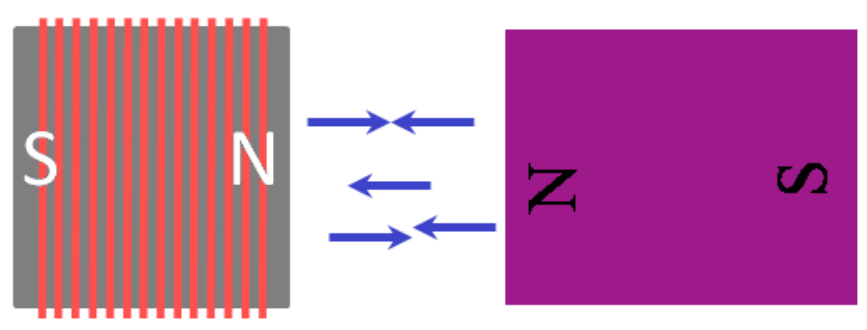

4. If the electromagnet is fully magnetized. The permanent magnet will not attract it. Full repulsion force will be got. Figure:

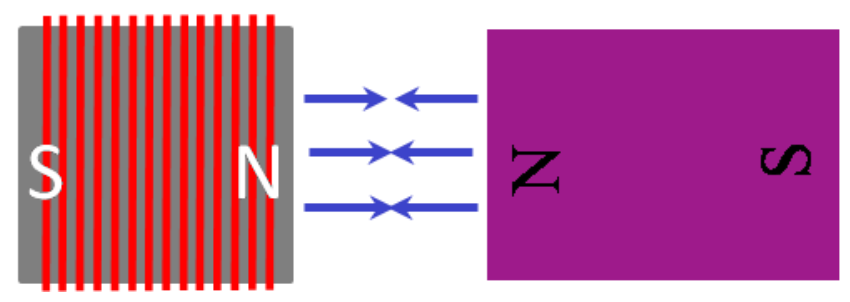

Note: this same phenomenon happens when a saturated permanent magnet interact with such permanent magnet that have lost some of its magnetization. In this case the saturated permanent magnet attracts un-magnetized part of the weak permanent magnet. Consequently, we observe repulsion between two unlike poles of two different permanent magnets; when they are very near to each other. 


\section{The unexpected efficiency and laws of motion}

No present rule of electromagnetism justifies this extra efficiency. For example: $I^{\wedge} 2 R$ loss increases as a result of increment in current so efficiency must drop but it does increase instead!

I have tried hard to find suitable laws of science to validate this extra efficiency. In this attempt I have applied the laws of motion on magnetic repulsion and attraction forces between an electromagnet and permanent magnet. The laws of motion govern all kinds of forces. So, Magnetic force must abide by the laws, too.

As I expected, the laws of motion justify the extra efficiency sufficiently. According to the laws of motion, the emerging of the extra efficiency is absolutely natural.

\section{Calculations of net forces appearing in all the three experiments in accordance with first law of motion Related explanations of First Law of Motion:}

"To determine if the forces acting upon an object are balanced or unbalanced, an analysis must first be conducted to determine what forces are acting upon the object and in what direction.

If two individual forces are of equal magnitude and opposite direction, then the forces are said to be balanced. An object is said to be acted upon by an unbalanced force only when there is an individual force that is not being balanced by a force of equal magnitude and in the opposite direction. A resultant force is the difference between two forces. The size of the overall force acting on an object is called the resultant force."

For production of continuous motion between an electromagnet and permanent magnet, full cycles of attraction and repulsion are needed. So we have to determine:

1. What force or forces are produced during repulsion and what is net force of repulsion?

2. What force or forces are produced during attraction and what is net force of attraction?

Once we get the net forces of attraction and repulsion, we can easily get total net force of a complete cycle of attraction and repulsion by adding the two net forces.

\section{Net force of repulsion}

The electromagnet used in all the three experiment is never saturated. So the electromagnet remains partially magnetized in all the three experiment. However, its degree of magnetization differs in each experiment.

Pole of the permanent magnet repels magnetized part of the iron-core of the electromagnet because of like-polarity but attracts the un-magnetized part of the iron-core. This is attraction during repulsion.

Forces that are produced when the electromagnet and the permanent magnets repel each other 
1. The flux of the electromagnet repels like flux of the permanent magnet. This is repulsion force of electromagnet.

2. The flux of the permanent magnet repels like flux of electromagnet this is repulsion force of permanent magnet.

3. The pole of the permanent magnet attracts un-magnetized part of the iron. This is attraction force of permanent magnet during repulsion

\section{Attraction force of PM during repulsion}

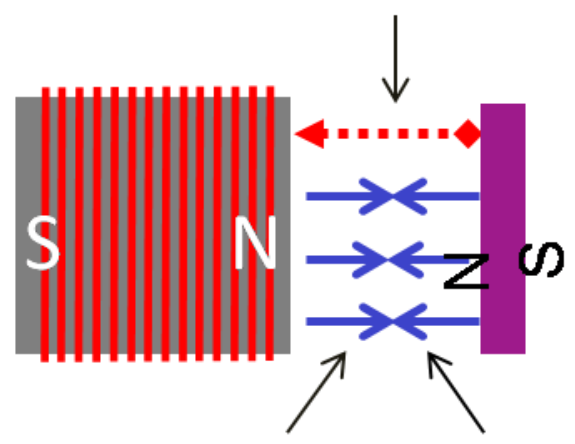

\section{Repulsion force of EM}

\section{Repulsion force of PM}

\section{Total applied force in this system}

- Total applied force is a combination of three forces in this system.

- Repulsion force created by electromagnet

- Repulsion force created by PM.

- "Attraction force during repulsion" created by PM.

- All the three forces are produced simultaneously between the electromagnet and the permanent magnet. So, total of quantities of all the three forces is total applied force in this system.

\section{Matching and opposing forces in this system}

\section{Matching force that is present in this system}

While, one of the PM and EM is free to move and the other one is fixed, repulsion forces of EM and PM move the movable object to the same desired direction. So, the two repulsion forces are matching forces.

Opposing force that is present in this system 


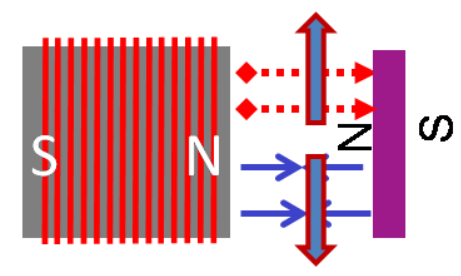

Direction of attraction force of permanent magnet is opposite to the direction of repulsion force

Attraction force (produced between the same like poles) is opposing force, because it moves the movable object against desired direction.

\section{Balanced force that is present in this system}

- Equivalent part of repulsion force (that is a combination of repulsion forces of EM and PM) must be balanced equally by opposing force of attraction. So, a total of "amount of the opposing attraction force plus amount of the repulsion force balanced by the opposing force" is balanced force in this system. Figure:

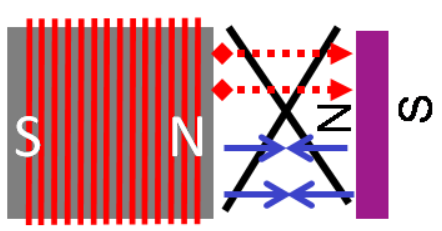

Repulsion force is wasted because both opposite forces balance each other.

Total unbalanced force that is present in this system

- Total applied force minus balanced force is total unbalanced force in this system.

- While judging total Unbalanced force, the formula $F=m a$ does not apply

Additional force that is present in this system

- Attraction during repulsion is caused by permanent magnet only.

- Permanent magnet causes repulsion force against the repulsion force of electromagnet

- Both these forces are additional than the force created by electromagnet.

- Thus: 
- Additional force is present in the system side by side the force created by input electricity .

\section{Relation between 'degree of magnetization of iron core of electromagnet' and balance of force}

\section{Effect of higher degree of magnetization of iron core}

At higher magnetization of the iron-core:

- Non-magnetized part is reduced.

- Reduced non-magnetized part allows lesser flux of permanent magnet to penetrate into.

- Attraction during repulsion is also reduced accordingly.

- Reduced 'attraction during repulsion' balances a smaller part of repulsion.

- It means that the size of balanced force is reduced and resultant force increases accordingly.

\section{Effect of lower degree of magnetization of iron core}

\section{At lower magnetization of the iron-core, this process is reversed.}

- At lower magnetization a bigger part of the iron core remains un- magnetized. Permanent magnet attracts it forcefully. Attraction during repulsion (opposing force) is heavy. Balance of force is greater, so resultant force is weaker.

\section{Highlights}

- At higher magnetization of the iron-core:

- A reasonable part of repulsion force created by electromagnet is released from balanced force.

- A reasonable part of repulsion force created by PM is also released from balanced force.

- A reasonable part of "Attraction force during the period of repulsion" created by PM is also changed into resultant force.

- It is apparent once the iron-core is fully magnetized (saturated), permanent magnet will not find any non- magnetized iron to attract. The opposing force of attraction during repulsion cannot come into existence in this situation. No balance (cancelation) of force will occur.

- Electromagnet will repel the permanent magnet with all its force and the permanent magnet will repel the electromagnet with all its force.

- Sum of both repulsion forces will be got as resultant force.

\section{Special conclusions}

No payment for attraction force of static magnetic field 
- It is very wrongly thought that "we have to pay for the free attraction (when permanent magnet attract an electromagnet -without-current). We have to give current for repulsion since without repulsion there will be no work."

- We do not have to pay any thing for the free attraction because current given for repulsion force creates not only its own repulsion force but also activates repulsion force of permanent magnet. The amount of the joint repulsion force is always enough to pay for the current.

- However, opposing attraction force during repulsion must be controlled. It is always controllable.

\section{Reason of very weak efficiency in experiment 1}

\section{Repulsion force that was produced in this experiment}

Very low current level and only one permanent was used in this experiment. A heavy part of the ironcore remained un-magnetized because of the very low level of current. Heavy amount of un-magnetized iron allowed heavy amount of PM flux to penetrate into.

A fraction of the flux of permanent magnet repelled the like flux of electromagnet and remainder flux penetrated into the un- magnetized iron. (However, remainder flux of only one permanent magnet was available to penetrate into the un- magnetized iron.)

Heavy amount of 'attraction during repulsion' was produced during this experiment. This 'attraction during repulsion' balanced equal part of repulsion. Heavy part of repulsion force was wasted in this experiment because of the heavy balance of force.

On the other hand, heavy amount of balanced force was produced in this experiment. It means that heavy amount of repulsion force turned into waste/garbage instead of working.

Very weak net repulsion force was produced in experiment number 1, because of wastage of heavy part of total repulsion force.

\section{Basic cause of weak efficiency of this experiment}

1. Very weak repulsion force was capable of pushing only a single permanent magnet in this experiment.

2. Attraction force of only one permanent magnet was got because of the weak repulsion.

3. Short capacity of using attraction force is responsible for the weak efficiency.

\section{Reason of greater efficiency in experiment 2}

A higher level of current and double permanent magnets was used in this experiment. Higher level of current reduced un-magnetized part of the iron core. It allowed lesser PM flux to penetrate into the iron. On the other hand, flux of the double permanent magnet penetrated into the iron with double 
force. Though scope for penetration of PM flux had been reduced by enhanced current level but force of PM flux was doubled, too.

Resultantly nearly the same amount of 'attraction during repulsion' was produced and the same amount of force was balanced (wasted) in this experiment as occurred in experiment 1.

At higher level of current, higher amount of repulsion force produced in this experiment. Ratio between input electricity and out put repulsion force remained approximately similar to experiment 1.

In experiment 1, we applied lesser current and got lesser out put repulsion force, in this experiment we applied higher input and got higher amount of out put repulsion force. Efficiency of current for production of repulsion force remained approximately similar in both experiments.

What benefit we got in this experiment?

We get attraction force of two permanent magnets instead of that of the single permanent magnet.

\section{Basic cause of higher efficiency that was appeared in this experiment}

1. Higher repulsion force was capable of pushing double permanent magnet instead of a single permanent magnet.

2. Attraction force of double permanent magnet was got.

3. Higher capacity of using attraction force is responsible for the higher efficiency.

\section{Experiment 3 verifies the reasons of the different efficiencies}

This is a verifying experiment. This experiment verifies that similar results like those of experiment 2 are always achievable if all situations are controlled accordingly.

\section{Result}

Balanced force during all the three experiments remained approximately the same.

As current level was enhanced gradually during the experiments, more repulsion force was produced.

Repulsion force increased gradually and substantially, but balanced force during all the three experiments remained approximately the same.

Resultant force increased untimely. It appeared in output. Extra efficiency produced.

\section{More explanations}


In all these three experiments only two factors remained variable: All other factors remained the same.

1: Permanent magnets were added gradually.

2: Current level was also enhanced because flux of permanent magnet was enhanced. (Repulsion did not happen properly using previous level of current).

\section{Situation when current increased}

At high level of current, higher magnetization was produced in the iron. Higher magnetization produced two-fold effect.

1. Higher magnetization reduced the scope for penetration of PM flux lines. Remnant attraction reduced accordingly. Reduction of remnant attraction restored repulsion force relatively. Repulsion became stronger. So, a part of the increased repulsion was ' $\underline{\text { restored', }}$ not created.

2. On the other hand, higher magnetization of the iron produced more flux. More flux produced more repulsion force between the magnets.

Additional repulsion force produced by the two -fold action of higher magnetization, allowed using of more PM flux. More PM flux produced more attraction, so total efficiency of a complete cycle of attraction and repulsion increased.

Because of the two- fold effect, more output power was produced than the consumed current. Additional force for additional efficiency came from unbalancing of the balanced force, not from current.

\section{Situation when current decreased}

(When we study the experiment inversely_from the experiment 3 to the experiment )

When current decreases, not only flux of electromagnet is reduced but also 'attraction during repulsion' is enhanced. So, balanced force is enhanced, too. This is the reverse situation of the twofold effect. In this reverse situation, we face not only weaker production of flux in electromagnet but also face increased loss of repulsion force because of increment in balanced force.

When reverse situation of the two- fold action occurs, workable force of permanent magnet changes into 'attraction during repulsion,' instead. So we get a loss instead of profit. Lesser output power is produced than the consumed current. Resultantly, efficiency decreases significantly.

It means that the real reason/ hindrance in recovery of permanent magnet force, is 'attraction during repulsion'. If it is reduced by one way or another, higher resultant force will be got. Otherwise balance of force will reduce resultant force.

Importance of repulsion force 
Maximum mechanical force of a complete cycle of attraction and repulsion is recovered only when repulsion force is recovered properly. Attraction needs a proper distance between interacting magnets to show its full strength.

If repulsion is weak, it will not produce sufficient distance between the magnets. Resultantly attraction will also be weak. If there is weak repulsion there is weak attraction so there is weak continuous motion. All this process will produce weak efficiency.

\section{Data of experiments}

\section{List}

- Magnetic power measuring device

- The same situations and conditions for all experiments

- Experimental devices used in this series of experiments

- Glossary of terms

- Method of an experiment

- Tables of data and comparison

- Specifications and explanations

\section{Magnetic power measuring device}

I have developed a device. One electromagnet and one permanent magnet can repel or attract each other in a controlled situation, using this device. This device gathers necessary data of a repulsion or attraction interaction. Input and output is calculated after an interaction is completed.

Pictures of the power measuring device

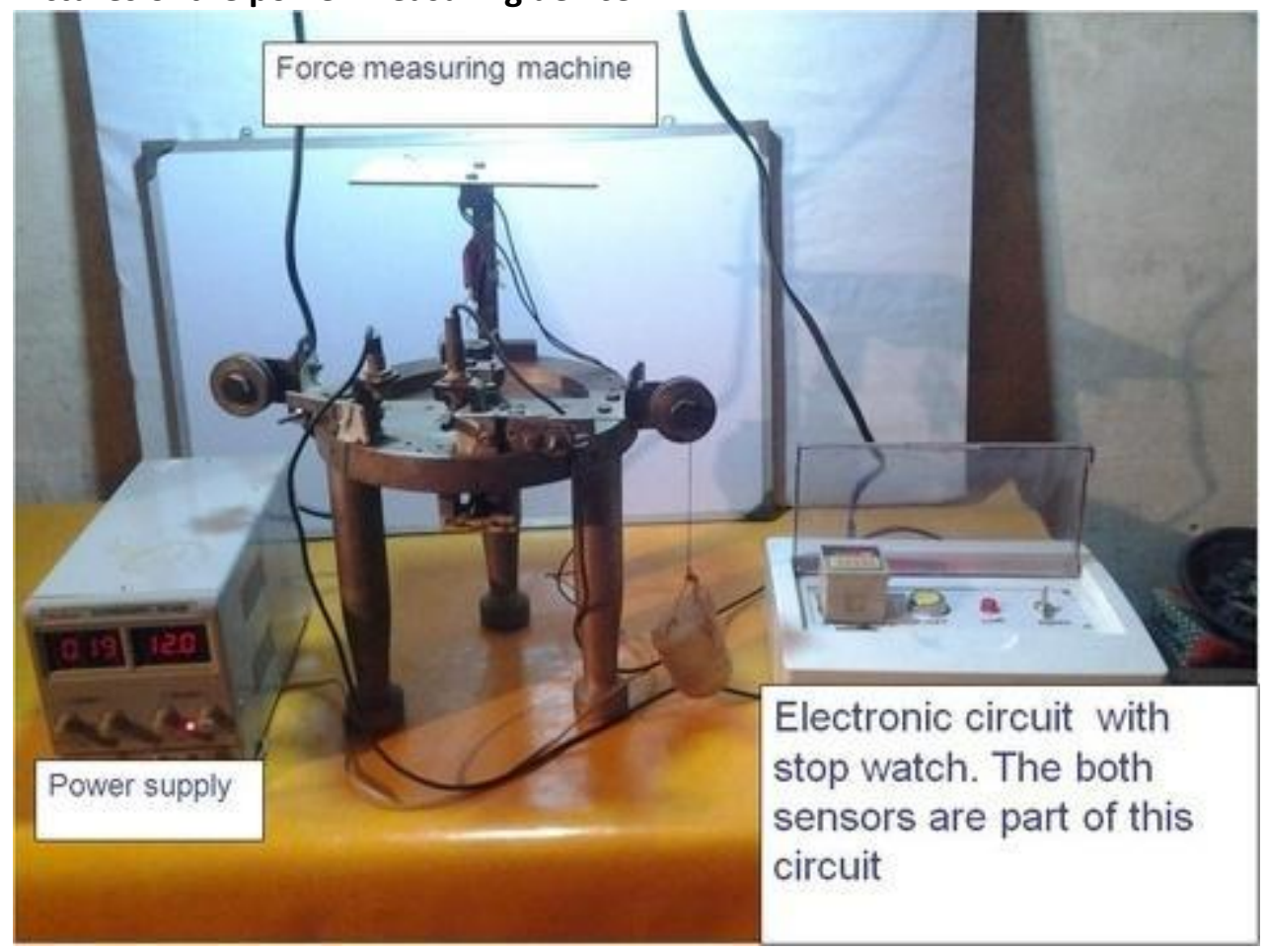




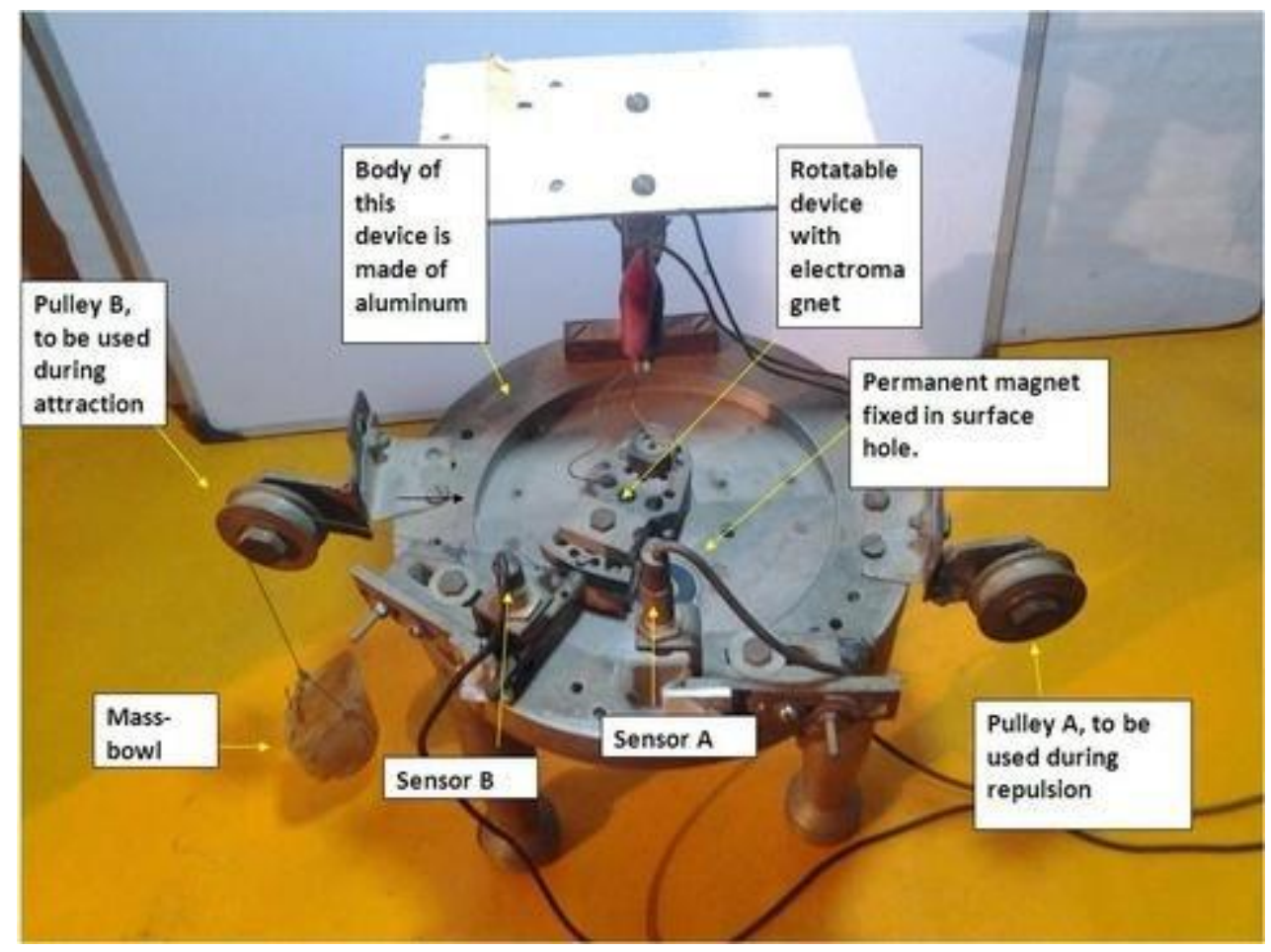

Link for exact sizes and functions of this device:

https://drive.google.com/file/d/OB3vaD073FnNxNENSdVI3c2tRSjA/view?usp=sharing

Link for a sample video of function of this device:

https://drive.google.com/folderview?id=0B3vaD073FnNxNWt0QmVXaOZDVkE\&usp=sharing

Link for detailed videos of this

device:https://drive.google.com/drive/folders/OB3vaD073FnNxNWt0QmVXa0ZDVkE?usp=sh aring

Discussion on the Power measuring device, Link:

https://www.quora.com/How-can-we-calculate-output-mechanical-force-of-a-two-magnetinteraction-is-it-enough-to-collect-data-about-mass-distance-and-time-of-the-interaction-andcalculate-it-properly

\section{The same situations and conditions for all experiments}

This series of experiment comprised upon 7 experiments. Each experiment comprised upon three interactions: repulsion interaction; attraction interaction using current; attraction interaction without current.

The same input current was used to conduct both repulsion and attraction interactions of an experiment 


\section{Factor of actuator}

A knob is part of the power measuring device. This knob is installed on the shaft. The Electromagnet is fixed on this knob. This knob with electromagnet may be named as 'actuator'. Mass of this actuator is $0.342 \mathrm{~kg}$. Arm of force is $43 \mathrm{~mm}$. Input current has to carry not only the load but also has to rotate the mass of actuator, too. To calculate real input for a load or real output of an interaction, mass of the actuator has to be subtracted.

\section{Deduction of provisional mass of the actuator}

As scientific calculations were not available to measure the active mass of the actuator, a provisional mass was achieved using bellow given method.

- Active mass of the actuator was measured without presence of current and permanent magnets.

- A mass of $0.044 \mathrm{~kg}$ was put into the bowl. Sensor circuit was put-on. The actuator was released. It crossed the distance between both sensors as the mass dragged it.

- The actuator was dragged by $0.044 \mathrm{~kg}$ mass. It crossed 0.25 meter within 0.16 second.

- That is $=: 0.044 \mathrm{~kg}, 0.025 \mathrm{~m}, 0.16 \mathrm{~s}=\left(0.044 \mathrm{~kg} \times 0.025 \mathrm{~m} \times 9.8 \mathrm{~m} / \mathrm{s}^{\wedge} 2\right) / 0.16 \mathrm{~s}=0.06737$ watt

The same mass $(0.044 \mathrm{~kg})$ was used in all experiments as provisional mass of the actuator.

\section{General conditions}

- Mass of hanging mass-bowl was treated to be part of mass of actuator.

- For a repulsion interaction, minimum input was used. Repulsion did not happen at lower current than this minimum current.

- For all interactions in this experiment only Direct Current was used.

\section{Glossary of terms used to state quantities of this series of experiments}

PeG= Grass input power for interaction = Volts*Amperes=Watts= Total input power applied to a mechanical interaction of an experiment, including $\mathrm{I}^{\wedge} 2 \mathrm{R}$ loss in the coil's resistance (coil of the electromagnet).

$\mathbf{R}=$ Resistance in the coil=(Steady state resistance $=3.00 \mathrm{Volts} / 00.20 \mathrm{Ampere}=15)$

$\operatorname{Pr}=\mid \wedge 2 R$ loss $=l e^{*} \mid e^{*} R$

$\mathbf{P e N}=$ Net input power $=\mathbf{P e G}-\mathbf{P r}=$ net input power applied to an interaction after subtraction of $\mathrm{I}^{\wedge} 2 \mathrm{R}$ loss

Watt-second $=\mathbf{P e N}$ *second= net input power multiplied by time of an interaction

\section{Experimental devices used in this series of experiments}

1. Magnetic power measuring device (already specified in this document). 
2. Three permanent magnets made of the same material (grade $33 \mathrm{SH}$ ), size:

$\mathrm{D} 25 \mathrm{~mm} * \mathrm{~d} 12 \mathrm{~mm} * 2 \mathrm{~mm}$; Magnetization: through $2 \mathrm{~mm}$. (ring shape).

3. One electromagnet: in all the interactions only one and the same electromagnet interacted with all kinds of permanent magnets.

Specification of electromagnet used in this experiment

- Material: soft iron; Weight of iron: 80.40 grams; Total length of iron core: $43 \mathrm{~mm}$

- Material of coil: copper

- Turns of wire: 992; Wire number: 30

- $\quad$ Steady state resistance $(R)=3.00$ volts $/ 00.20$ ampere $=15$

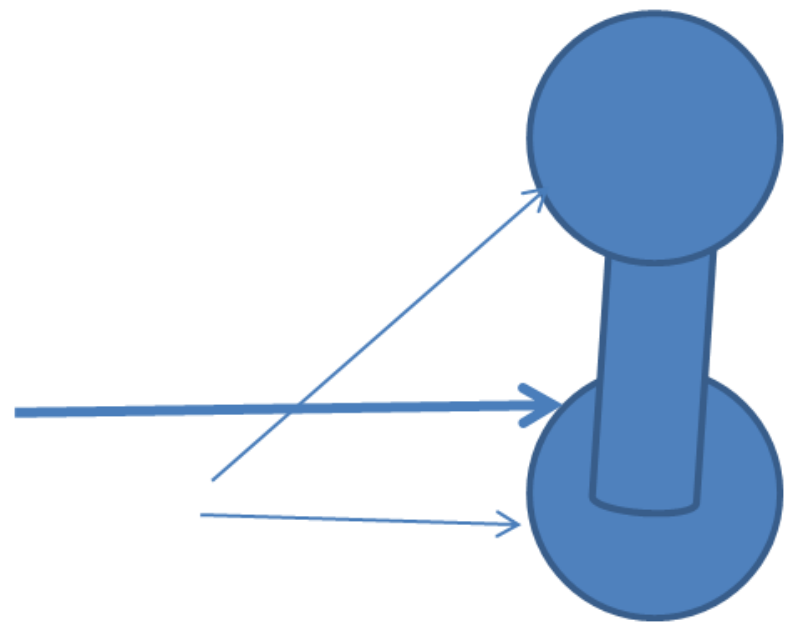

- Shape and size of iron core:

- Size of bar: D16mm*35mm

- Size of each side tablet: D25mm*4mm

\section{Permanent magnets assembled for the experiments}

For each of the experiments, a special permanent magnet was assembled. These permanent magnets were assembled to make a single magnet. Detail:

Experiment No. 1=only one saturated permanent magnet

Experiment No. 2 = two saturated permanent magnets were added together.

Experiment No.3 $=$ Three saturated permanent magnets were added together . 


\section{Method of an experiment}

\section{How to conduct a magnetic interaction using power measuring device}

Permanent magnet is fixed into the hole on the surface of the device. Electromagnet is fixed in the rotatable knob (Actuator).

\section{Interaction in attraction mode}

Appropriate mass is put into the mass bowl.

The actuator is brought by hand in the fixed range of the electronic sensor $B$. Now the electromagnet is set automatically at a distance of $1 \mathrm{~mm}$ away from the permanent magnet. Sensor circuit is put-on using line current. Watch is set on 0.00 of $1 / 100$ second.

Line current for electromagnet is put-on. Direction of current is set for attraction.

As soon as the electromagnet-knob is released, sensor B is activated automatically and it puts-on the stopwatch.

The electromagnet moves and its face come exactly opposite to the face of permanent magnet. When the interaction is completed, sensor A is activated automatically and puts-off the stopwatch.

\section{Interaction in repulsion mood}

Above process is reversed for repulsion.

\section{Interactions when attraction happened without current}

During each of these experiments an interaction of attraction without current was also conducted. Current was given for repulsion only. Repulsion happened and electromagnet crossed away permanent magnet. When current was put-off, permanent magnet attracted the iron of electromagnet back. This way a complete cycle of repulsion and attraction happened. Real output of each of these interactions is a combination of output powers of both repulsion with current and attraction without current.

It is apparent that to establish a continuous motion, complete cycle of attraction and repulsion is needed. If there is no repulsion there is no continuous motion. On the other hand once repulsion happens, happening of attraction is must, too. So output of attraction of permanent magnet without current depends upon not only enough repulsion but also it is an inescapable result of repulsion. Benefit of free attraction is fundamental part of total output of such kind of magnetic interaction. 


\section{Tables}

Table 4: data of experiment 1

\begin{tabular}{|c|c|c|c|c|}
\hline \multicolumn{5}{|c|}{$\begin{array}{l}\text { Electromagnet: the same } \\
\text { permanent magnet: only one saturated permanent magnet } \\
\text { Steady state resistance }=15, \text { Provisional mass of actuator }=0.044 \mathrm{~kg}\end{array}$} \\
\hline \multicolumn{5}{|c|}{ Input power applied to interaction of repulsion } \\
\hline \multicolumn{2}{|c|}{$\begin{array}{l}\text { Grass input power applied to the } \\
\text { electromagnet }(\mathrm{PeG})\end{array}$} & \multicolumn{2}{|l|}{ Volts*amperes=watts } & $19.00 * 1.11=21.09$ \\
\hline \multicolumn{2}{|c|}{$I^{\wedge} 2 \mathrm{R}$ loss $(\mathrm{Pr})$} & \multicolumn{2}{|l|}{ le*le* $R$} & $1.11 * 1.11 * 15=18.4815$ \\
\hline \multicolumn{2}{|c|}{ Net input power (PeN) } & \multicolumn{2}{|l|}{ PeG -Pr } & $21.09-18.4815=2.6085$ \\
\hline \multicolumn{2}{|c|}{ Input in watt-second } & \multicolumn{2}{|l|}{ PeN *time } & $2.6085 * 0.16=0.41736$ \\
\hline \multicolumn{5}{|c|}{$\begin{array}{l}\text { Output power of interaction of repulsion } \\
\text { Mass }=\text { Provisional mass of actuator: } 0.044 \text {, mass of total load lifted: } 0.005 \text {, distance }=0.025 \mathrm{~m} \text {, } \\
\text { time }=0.16 \mathrm{~s}\end{array}$} \\
\hline Output power & \multicolumn{2}{|c|}{$\begin{array}{l}\text { (Provisional mass of Actuator+ mass of load) } \\
* \text { distance/time }=\text { Watt }\end{array}$} & \multicolumn{2}{|c|}{$\begin{array}{l}(0.044+0.005) \mathrm{kg} \times 0.025 \mathrm{~m} \times 9.8 \\
\left.\mathrm{~m} / \mathrm{s}^{\wedge} 2\right) / 0.16 \mathrm{~s}=0.07503125\end{array}$} \\
\hline \multicolumn{5}{|c|}{ Input power applied to interaction of attraction } \\
\hline \multicolumn{5}{|c|}{ Both interactions of this experiment were conducted on the same input and for the same time. } \\
\hline \multicolumn{2}{|c|}{ Input in watt-second } & eN *time & & $2.6085 * 0.16=0.41736$ \\
\hline \multicolumn{5}{|c|}{$\begin{array}{l}\text { Total mass lifted by the actuator }=0.062 \mathrm{~kg} \text {, mass lifted by the actuator without current }= \\
0.005 \mathrm{~kg} \text {, mass lifted by current }=0.057 \mathrm{~kg} \text {, distance }=0.025 \mathrm{~m} \text {, time }=0.16 \mathrm{~s}\end{array}$} \\
\hline $\begin{array}{l}\text { Total output } \\
\text { power with current } \\
\text { (Pout.I) }\end{array}$ & \multicolumn{3}{|c|}{$\begin{array}{l}\text { (Provisional mass of actuator+ mass of total load } \\
\text { lifted) }{ }^{*} \text { distance/time=watt }\end{array}$} & $\begin{array}{l}(0.044+0.062) \mathrm{kg} \times 0.025 \mathrm{~m} \times \\
\left.9.8 \mathrm{~m} / \mathrm{s}^{\wedge} 2\right) / 0.16 \mathrm{~s}=0.1623125\end{array}$ \\
\hline $\begin{array}{l}\text { Output power } \\
\text { without } \\
\text { current(Pout.a) }\end{array}$ & \multicolumn{3}{|c|}{$\begin{array}{l}\text { (Provisional mass of actuator+ mass of load lifted } \\
\text { without current)*distance/time=Watt }\end{array}$} & $\begin{array}{l}(0.044+0.005) \mathrm{kg} \times 0.025 \mathrm{~m} \times \\
\left.9.8 \mathrm{~m} / \mathrm{s}^{\wedge} 2\right) / 0.16 \mathrm{~s} \\
=0.07503125\end{array}$ \\
\hline $\begin{array}{l}\text { Output power of } \\
\text { attraction of } \\
\text { current }\end{array}$ & \multicolumn{3}{|c|}{ (Pout.I)- (Pout.a) } & $\begin{array}{l}0.1623125-0.07503125 \\
=0.08728125\end{array}$ \\
\hline
\end{tabular}


Table 5: data of experiment 2

Electromagnet: the same permanent magnet: two saturated permanent magnets were added together Steady state resistance $=15$, Provisional mass of actuator $=0.044 \mathrm{~kg}$

Input power applied to interaction of repulsion

\begin{tabular}{|l|l|l|}
\hline $\begin{array}{l}\text { Grass input power applied to the } \\
\text { electromagnet }(\mathbf{P e G})\end{array}$ & Volts*amperes=watts & $21.00 * 1.16=24.36$ \\
\hline $\mathrm{I}^{\wedge} 2 \mathrm{R}$ loss $(\mathrm{Pr})$ & le*le $* \mathbf{R}$ & $1.16^{*} 1.16 * 15=20.184$ \\
\hline Net input power (PeN) & PeG $-\mathrm{Pr}$ & $24.36-20.184=4.176$ \\
\hline Input in watt-second & PeN $*$ time & $4.176 * 0.14 \mathrm{~s}=0.58464$ \\
\hline
\end{tabular}

Output power of interaction of repulsion

Mass $=$ Provisional mass of actuator: 0.044 , mass of total load lifted: 0.005 , distance $=0.025 \mathrm{~m}$, time $=0.14 \mathrm{~s}$

\begin{tabular}{l|l|l}
\hline $\begin{array}{l}\text { Output } \\
\text { power }\end{array}$ & $\begin{array}{l}\text { (Provisional mass of Actuator+ mass of load) } \\
* \text { distance/time=Watt }\end{array}$ & $\begin{array}{l}(0.044+0.005) \mathrm{kg} \times 0.025 \mathrm{~m} \times 9.8 \\
\left.\mathrm{~m} / \mathrm{s}^{\wedge} 2\right) / 0.14 \mathrm{~s}=0.08575\end{array}$
\end{tabular}

Input power applied to interaction of attraction

Both interactions of this experiment were conducted on the same input and for the same time.

\begin{tabular}{l|l|l} 
Input in watt-second & PeN *time & $4.176 * 0.14 \mathrm{~s}=0.58464$
\end{tabular}

\section{Output power of interaction of attraction}

Total mass lifted by the actuator $=0.155 \mathrm{~kg}$, mass lifted by the actuator without current= $0.057 \mathrm{~kg}$, mass lifted by current $=0.098 \mathrm{~kg}$, distance $=0.025 \mathrm{~m}$, time $=0.14 \mathrm{~s}$

\begin{tabular}{|l|l|l|}
\hline $\begin{array}{l}\text { Total output } \\
\text { power with } \\
\text { current (Pout.I) }\end{array}$ & $\begin{array}{l}\text { (Provisional mass of actuator+ mass of total load } \\
\text { lifted) *distance/time=watt }\end{array}$ & $\begin{array}{l}(0.044+0.155) \mathrm{kg} \times 0.025 \mathrm{~m} \mathrm{~m} \\
\left.9.8 \mathrm{~m} / \mathrm{s}^{\wedge} 2\right) / 0.14 \mathrm{~s}=0.34825\end{array}$ \\
\hline $\begin{array}{l}\text { Output power } \\
\text { without } \\
\text { current(Pout.a) }\end{array}$ & $\begin{array}{l}\text { (Provisional mass of actuator+ mass of load lifted } \\
\text { without current)*distance/time=Watt }\end{array}$ & $\begin{array}{l}(0.044+0.057) \mathrm{kg} \times 0.025 \mathrm{~m} \times \\
\left.9.8 \mathrm{~m} / \mathrm{s}^{\wedge} 2\right) / 0.14 \mathrm{~s}=0.17675\end{array}$ \\
\hline $\begin{array}{l}\text { Output power of } \\
\text { current }\end{array}$ & (Pout.I)- (Pout.a) & $0.34825-0.17675=0.1715$ \\
\hline
\end{tabular}


Table 6: data of experiment 3

\begin{tabular}{|c|c|c|c|c|}
\hline \multicolumn{5}{|c|}{$\begin{array}{l}\text { Electromagnet: the same } \\
\text { permanent magnet: Three saturated permanent magnets we } \\
\text { Steady state resistance }=15, \text { Provisional mass of actuator }=0.0\end{array}$} \\
\hline \multicolumn{5}{|c|}{ Input power applied to interaction of repulsion } \\
\hline \multicolumn{2}{|c|}{$\begin{array}{l}\text { Grass input power applied to the } \\
\text { electromagnet (PeG) }\end{array}$} & \multicolumn{2}{|l|}{ Volts*amperes=watts } & $24.00 * 1.33=31.92$ \\
\hline \multicolumn{2}{|c|}{$I^{\wedge} 2 \mathrm{R}$ loss $(\mathrm{Pr})$} & \multicolumn{2}{|l|}{ le*le *R } & $1.33 * 1.33 * 15=26.5335$ \\
\hline \multicolumn{2}{|c|}{ Net input power (PeN) } & \multicolumn{2}{|l|}{ PeG -Pr } & $31.92-26.5335=5.3865$ \\
\hline \multicolumn{2}{|c|}{ Input in watt-second } & \multicolumn{2}{|l|}{ PeN *time } & $5.3865 * 0.12=0.64638$ \\
\hline \multicolumn{5}{|c|}{$\begin{array}{l}\text { Output power of interaction of repulsion } \\
\text { Mass }=\text { Provisional mass of actuator: } 0.044 \text {, mass of total load lifted: } 0.005, \text { distance }=0.025 \mathrm{~m} \text {, } \\
\text { time }=0.12 \mathrm{~s}\end{array}$} \\
\hline \begin{tabular}{l|l} 
Output \\
power
\end{tabular} & \multicolumn{2}{|c|}{$\begin{array}{l}\text { (Provisional mass of Actuator+ mass of load) } \\
* \text { distance/time=Watt }\end{array}$} & \multicolumn{2}{|c|}{$\begin{array}{l}(0.044+0.005) \mathrm{kg} \times 0.025 \mathrm{~m} \times 9.8 \\
\left.\mathrm{~m} / \mathrm{s}^{\wedge} 2\right) / 0.12 \mathrm{~s}=0.10004\end{array}$} \\
\hline \multicolumn{5}{|c|}{ Input power applied to interaction of attraction } \\
\hline \multicolumn{5}{|c|}{ Both interactions of this experiment were conducted on the same input and for the same time. } \\
\hline \multicolumn{2}{|c|}{ Input in watt-second } & \multicolumn{2}{|c|}{ PeN *time } & $5.3865 * 0.12=0.64638$ \\
\hline \multicolumn{5}{|c|}{$\begin{array}{l}\text { Total mass lifted by the actuator }=0.255 \mathrm{~kg} \text {, mass lifted by the actuator without current }= \\
0.110 \mathrm{~kg} \text {, mass lifted by current }=0.145 \mathrm{~kg} \text {, distance }=0.025 \mathrm{~m} \text {, time }=0.12 \mathrm{~s}\end{array}$} \\
\hline $\begin{array}{l}\text { Total output } \\
\text { power with } \\
\text { current (Pout.I) }\end{array}$ & \multicolumn{3}{|c|}{$\begin{array}{l}\text { (Provisional mass of actuator+ mass of total load } \\
\text { lifted) } * \text { distance/time=watt }\end{array}$} & $\begin{array}{l}(0.044+0.255) \mathrm{kg} \times 0.025 \mathrm{mx} \\
\left.9.8 \mathrm{~m} / \mathrm{s}^{\wedge} 2\right) / 0.12 \mathrm{~s}=0.61045\end{array}$ \\
\hline $\begin{array}{l}\text { Output power } \\
\text { without } \\
\text { current(Pout.a) }\end{array}$ & \multicolumn{3}{|c|}{$\begin{array}{l}\text { (Provisional mass of actuator+ mass of load lifted } \\
\text { without current)* distance/time }=\text { Watt }\end{array}$} & $\begin{array}{l}(0.044+0.110) \mathrm{kg} \times 0.025 \mathrm{mx} \\
\left.9.8 \mathrm{~m} / \mathrm{s}^{\wedge} 2\right) / 0.12 \mathrm{~s}=0.31441\end{array}$ \\
\hline $\begin{array}{l}\text { Output power of } \\
\text { current }\end{array}$ & \multicolumn{3}{|c|}{ (Pout.I)- (Pout.a) } & $0.61045-0.31441=0.29604$ \\
\hline
\end{tabular}




\section{Necessary explanations}

\section{Efficiency of repulsion and efficiency of attraction}

- When a non-saturated electromagnet interacts with a saturated permanent magnet, ratio between efficiencies of repulsion and attraction depends upon the size of air gap between them.

- If air gap is wider, output power of repulsion will increase so efficiency of repulsion will also increase. On the other hand attraction will decrease so efficiency of attraction will also decrease.

- If air gape is narrower, output power of repulsion will decrease so efficiency of repulsion will also decrease. On the other hand attraction will increase so efficiency of attraction will also increase.

- As size of air gap can change ratio between efficiencies of repulsion and attraction, efficiency of any of repulsion or attraction can be extended to a maximum limit and efficiency of the other will automatically be reduced.

\section{Residual effect}

- The power measuring device is not capable to measure residual in electromagnet and its effect on output power. However other experiments conducted on another device indicate that if there is any residual in the electromagnet, polarity of residual changes suddenly in accordance with change in direction of current. As direction of current during an experiment has to be changed to complete cycle of attraction and repulsion, establishment of any permanent polarity in the electromagnet does not seem possible. However residual produced by a period of attraction or repulsion may affect the output of the same period. 